Article

\title{
Anti-Inflammatory Activity Comparison among Scropoliosides-Catalpol Derivatives with 6-O-Substituted Cinnamyl Moieties
}

\author{
Tiantian Zhu ${ }^{1,2, \dagger}$, Liuqiang Zhang ${ }^{2, \dagger}$, Shuang Ling ${ }^{1}$, Fei Qian ${ }^{1,2}$, Yiming Li $^{2, *}$ and \\ Jin-Wen $X \mathbf{u}^{1, *}$
}

Received: 11 September 2015 ; Accepted: 7 October 2015 ; Published: 3 November 2015

Academic Editor: Derek J. McPhee

1 Murad Research Institute for Modernized Chinese Medicine, Shanghai University of Traditional Chinese

Medicine, Shanghai 201203, China; sweet-0801@hotmail.com (T.Z.); sarah_ling@126.com (S.L.);

qianfei0517@126.com (F.Q.)

2 School of Pharmacy, Shanghai University of Traditional Chinese Medicine, Shanghai 201203, China; 04100217@163.com

* Correspondence: ymlius@163.com (Y.L.); jinwen.xu88@gmail.com (J.-W.X.); Tel.: +86-21-5132-2191 (Y.L.); +86-21-5132-2532 (J.-W.X.); Fax: +86-21-5132-2193 (Y.L.); +86-21-5132-2446 (J.-W.X.)

$\dagger$ These authors contributed equally to this work.

\begin{abstract}
We have previously shown that scropolioside B has higher anti-inflammatory activity than catalpol does after the inhibition of nuclear factor (NF)- $\mathrm{kB}$ activity and IL-1 $\beta$ expression, maturation, and secretion. Various scropoliosides were extracted, isolated, and purified from Scrophularia dentata Royle ex Benth. We then compared their anti-inflammatory activities against LPS-induced NF- $\mathrm{kB}$ activity, cytokines mRNA expression, IL-1 $\beta$ secretion, and cyclooxygenase- 2 activity. The inhibitory effects of the scropoliosides varied depending on whether the 6-O-substituted cinnamyl moiety was linked to $\mathrm{C}^{\prime \prime} 2-\mathrm{OH}, \mathrm{C}^{\prime \prime} 3-\mathrm{OH}$, or $\mathrm{C}^{\prime \prime} 4-\mathrm{OH}$, and on the number of moieties linked, which is closely related to the enhancement of antiinflammatory activity. Among these compounds, scropolioside $\mathrm{B}$ had the strongest antiinflammatory effects.
\end{abstract}

Keywords: scropoliosides; 6-O-substituted cinnamyl moiety; antiinflammatory effect; NF-kB; cytokines

\section{Introduction}

Iridoids are a class of secondary metabolites found in a wide variety of various plants, such as Scrophulariaceae, Loganiaceae, Gentianaceae, Rubiaceae, Verbenaceae, and Oleaceae, etc. Iridoids have neuroprotective, antiinflammatory, immunomodulatory, hepatoprotective, cardioprotective, anticancer, antioxidant, antimicrobial, hypoglycemic, hypolipidemic, choleretic, antispasmodic, and purgative properties [1-4]. Hydrolyzed products of iridoid glycosides, harpagide and harpagoside, exhibited a dose-dependent inhibitory effect on cyclooxygenase-2 (COX-2) activity at $2.5-100 \mu \mathrm{mol} / \mathrm{L}$ [5]. Catalpol and aucubin are two of the most common iridoids and exhibit weak antiinflammatory effects [6]. At $500 \mu \mathrm{mol} / \mathrm{L}$, catalpol reduced the expression of proinflammatory mediators, such as monocyte chemotactic protein-1 (MCP-1), tumor necrosis factor- $\alpha$ (TNF- $\alpha$ )-inducible NO synthase, and the receptor for advanced glycation endproducts (AGE), and significantly reduced the transcriptional activation of nuclear factor (NF)- $\mathrm{KB}$ [7]. Fu et al. [8] reported that catalpol inhibited myeloperoxidase activity in lung samples and reduced mouse lung wet-to-dry weight ratio, the amounts of inflammatory cells, TNF- $\alpha$, IL-6, IL-4, and IL-1 $\beta$ in mouse bronchoalveolar lavage fluid, and the amount of alveolar macrophages in male 
BALB/c mice. Moreover, catalpol upregulated the production of IL-10 in bronchoalveolar lavage fluid and alveolar macrophages. Recently, we observed that scropolioside B, a catalpol derivative, effectively inhibited IL-1 $\beta$ and other cytokines expression at $50 \mu \mathrm{mol} / \mathrm{L}$ through NF- $\mathrm{KB}$ and NLRP3 pathways [9]. However, catalpol did not effectively inhibit NF-kB activity at the same concentration, suggesting that the antiinflammatory effect of scropolioside B is higher than that of catalpol. Bas et al. [10] also reported that scropolioside A $(100 \mu \mathrm{mol} / \mathrm{L})$ inhibited the production of $\mathrm{PGE}_{2}, \mathrm{LTB}_{4}, \mathrm{NO}$, IL-1 $\beta$, IL-2, IL-4, TNF- $\alpha$, and IFN- $\beta$; however, it did not affect the production of IL-10. However, because of the diversity of iridoid structure and lack of clarity about its relationship with the activity, we chose eight scropoliosides (Figure 1), namely scrodentoside A, B, and $\mathrm{D}, 6-O-\alpha-\mathrm{L}-\left(4^{\prime \prime}\right.$-O-trans- $p$-coumaroyl) rhamnopyranosylcatalpol (named scropolioside $\left.\mathrm{F}\right)$ [11], 6-O- $\alpha$-L-(4" $-O$-feruloyl) rhamnopyranosylcatalpol (scropolioside G) [12], 6-O- $\alpha$-L-(2" -O-feruloyl) rhamnopyranosylcatalpol (scropolioside H) [13], saccatoside [14], and 6-O-methylcatapol [15], which were isolated from Scrophularia dentata Royle ex Benth, and analyzed the effects of their structure-activity relationships on the antiinflammatory effect.

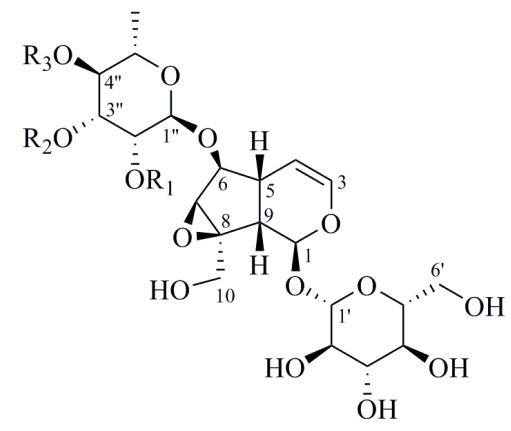

Scropolioside D: $\mathrm{R}_{1}=\mathrm{Ac}, \mathrm{R}_{2}=$ trans-cinnamoyl, $\mathrm{R}_{3}=\mathrm{Ac}$ Scropolioside $\mathrm{B}$ : $\mathrm{R}_{1}=\mathrm{Ac}, \mathrm{R}_{2}=\mathrm{R}_{3}=$ trans-cinnamoyl

Scrodentoside A: $\mathrm{R}_{1}=\mathrm{R}_{2}=\mathrm{Ac}, \mathrm{R}_{3}=$ trans-3,4-dimethoxycinnamoyl

Scrodentoside $\mathrm{F}$ : $\mathrm{R}_{1}=\mathrm{R}_{2}=\mathrm{H}, \mathrm{R}_{3}=$ trans-p-coumaroyl

Scrodentoside $\mathrm{G}: \mathrm{R}_{1}=\mathrm{R}_{2}=\mathrm{H}, \mathrm{R}_{3}=$ trans-feruloyl

Scrodentoside $\mathrm{H}$ : $\mathrm{R}_{1}=$ trans -feruloyl, $\mathrm{R}_{2}=\mathrm{Ac}, \mathrm{R}_{3}=\mathrm{H}$

Saccatoside: $\quad \mathrm{R}_{1}=$ trans-p-coumaroyl, $\mathrm{R}_{2}=\mathrm{Ac}, \mathrm{R}_{3}=\mathrm{H}$

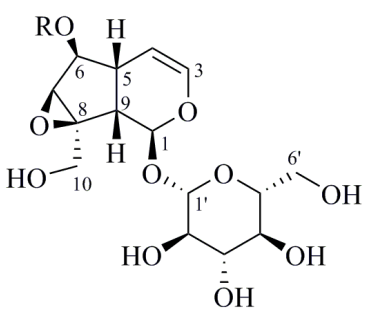

Methylcatapol: $\mathrm{R}=\mathrm{CH}_{3}$ catapol: $\mathrm{R}=\mathrm{H}$

Figure 1. Chemical structures of scropoliosides and catalpol.

\section{Results and Discussion}

\subsection{Effect of Iridoid Glycosides on NF-KB Activation}

Because all iridoid structures contain a catalpol skeleton (Figure 1), we compared and analyzed the antiinflammatory activities of iridoids and catalpol in HEK293 cells transfected with the luciferase reporter plasmid. To investigate the overall antiinflammatory activity of these monomers, we used a luciferase reporter assay to determine NF- $\kappa B$ activity. After HEK293 cells were transferred with $\mathrm{NF}-\mathrm{kB}$ or the control plasmid, the cells were incubated with or without the monomer for $1 \mathrm{~h}$ and then stimulated with $100 \mathrm{ng} / \mathrm{mL}$ of TNF- $\alpha$. The luciferase activity increased after stimulation with TNF- $\alpha$. Pretreatment with $50 \mu \mathrm{mol} / \mathrm{L}$ iridoid glycosides, but not catalpol, resulted in $40 \%-60 \%$ inhibitory effect on NF- $\mathrm{kB}$ luciferase reporter activity, suggesting that methyl- or glycoside-modified groups at the 6 site increase the ability of the compound to inhibit NF- $\mathrm{kB}$ activation (Figure 2). 


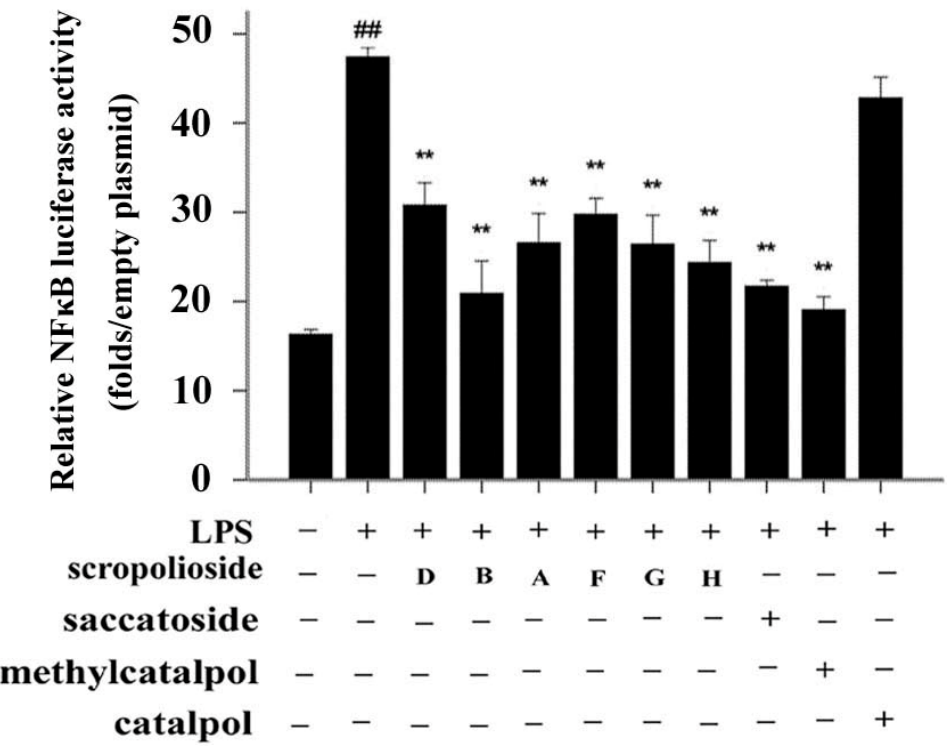

Figure 2. Effects of scropoliosides and catalpol on TNF- $\alpha$-induced NF- $\kappa B$ activation. Cells were preincubated for $1 \mathrm{~h}$ with $50 \mu \mathrm{mol} / \mathrm{L}$ scropoliosides or catalpol and then stimulated with $100 \mathrm{ng} / \mathrm{mL}$ of TNF- $\alpha$ for $16 \mathrm{~h}$. The results shown are representative of 3 repeated experiments. Data are expressed as means $\pm \mathrm{SD}$. \#\# $p<0.01$ vs. the control, ${ }^{* *} p<0.01$ vs. the TNF- $\alpha$ group.

\subsection{Cytokine Expression}

To understand the effect of these iridoid glycosides on cytokine expression, we selected three cytokines based on signaling pathways induced by LPS/TLR4 and different secretion time, namely IL-1 $\beta$, IL-8, and IFN- $\beta$, and examined the inhibitory effects of the iridoids. In lipopolysaccharides (LPS)-stimulated THP-1 monocytes, IL-1 $\beta$ expression increased rapidly within $2-4 \mathrm{~h}$, and IL-8 and IFN- $\beta$ expression presented a biphasic pattern with the late peak being higher than the previous peak and scrodentoside B only inhibiting the late peak (Figure 3). In the case of the THP-1 cells treated with various iridoids, scropoliosides $\mathrm{B}, \mathrm{F}$, and $\mathrm{G}$ and 6-O-methylcatapol significantly reduced IL-1 $\beta$ maturation and secretion in the clutured medium of the THP-1 cells (Figure 4A), and only scropoliosides A, B, and D inhibited IL-1 $\beta$ mRNA expression (Figure 4B). Our results showed that scropolioside B, but not other iridoids, inhibited IL-8 mRNA expression (Figure 4C) and that scropolioside B and catalpol reduced IFN- $\beta$ mRNA expression in the LPS-induced THP-1 cells (Figure 4D).
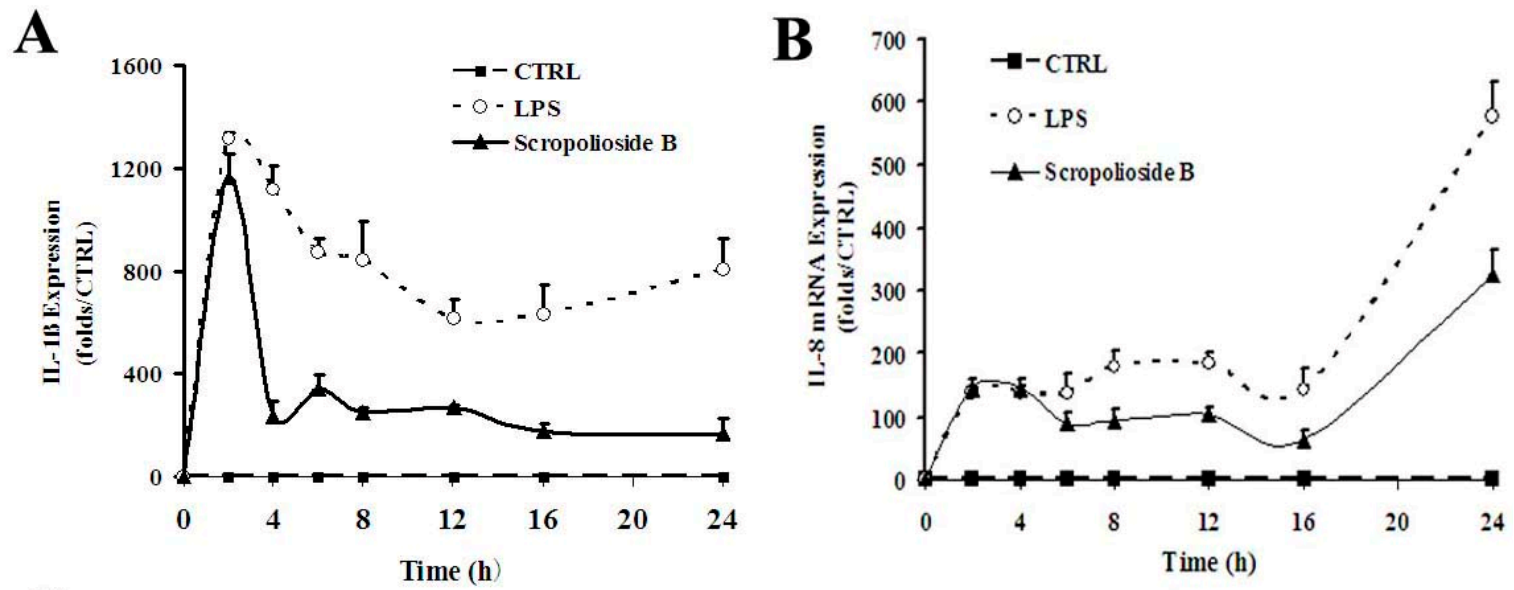

Figure 3. Cont. 


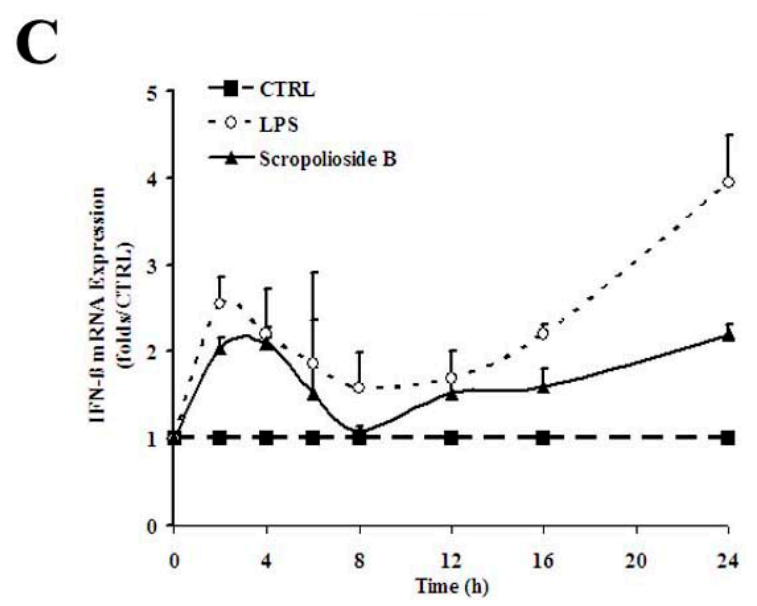

Figure 3. Kinetics of the inhibitory effect of scropolioside B on the expression of IL- $1 \beta$, IL- 8 , and IFN- $\beta$ in LPS-induced THP-1 cells. THP-1 cells were pretreated with $50 \mu \mathrm{mol} / \mathrm{L}$ scropolioside B for $1 \mathrm{~h}$ and then stimulated with LPS $(1 \mu \mathrm{g} / \mathrm{mL})$ for another $2,4,6,8,12,16$, or $24 \mathrm{~h}$. The mRNA expression of IL- $1 \beta$, IL- 8 , and IFN- $\beta$ was measured using real-time RT-PCR. The results shown are representative of three repeated experiments.
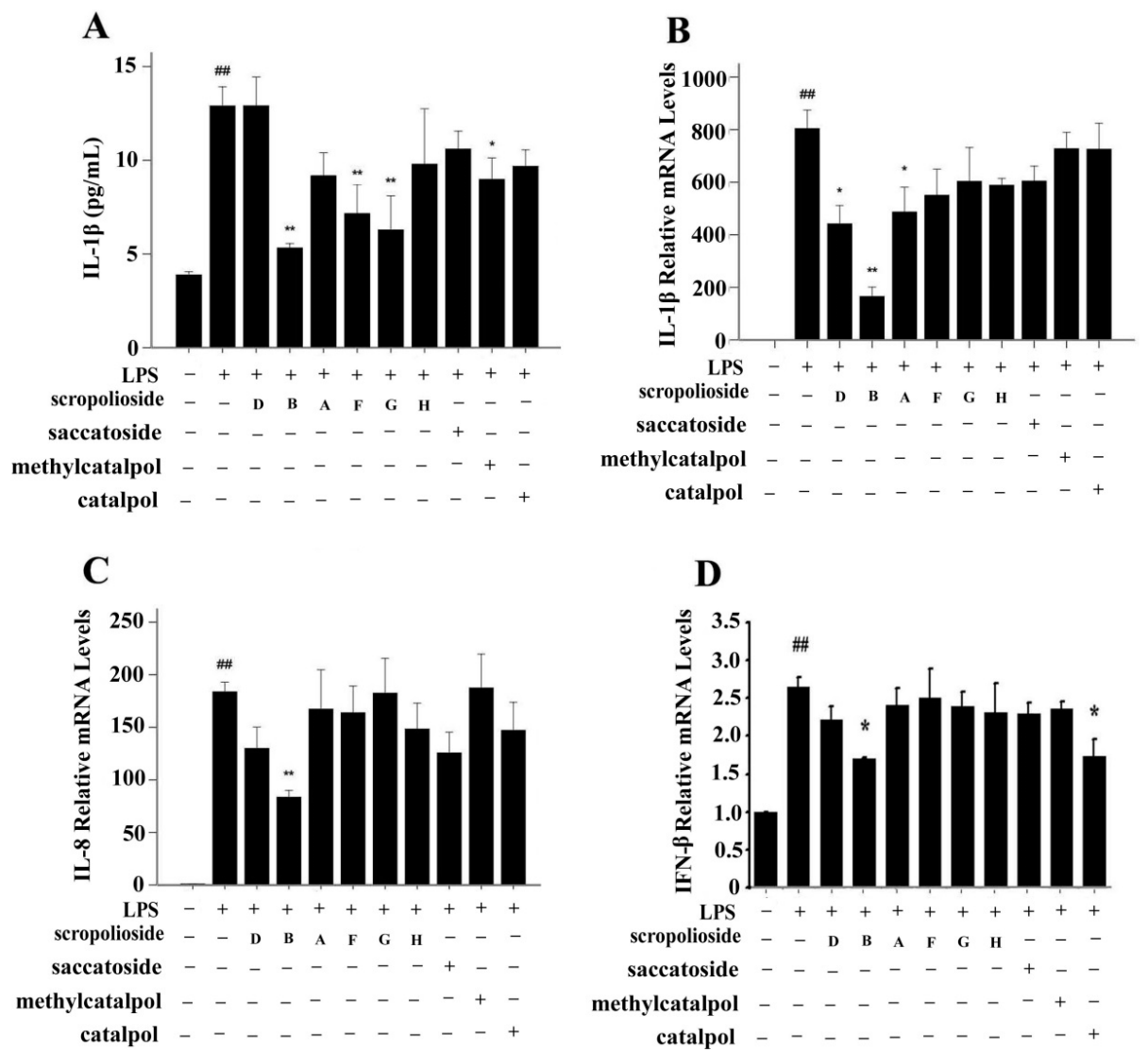

\section{D}

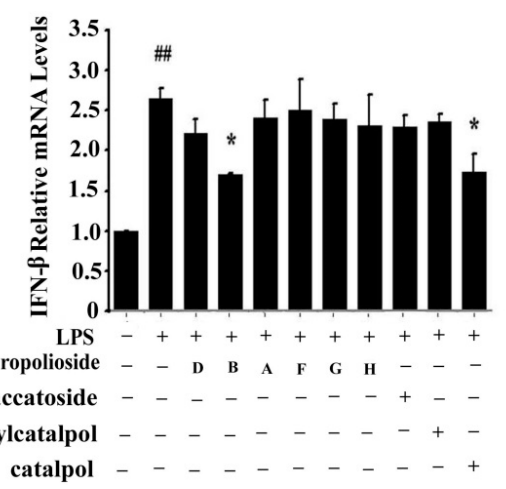

Figure 4. Effect of scropoliosides and catalpol on the expression of IL- $1 \beta$, IL-8, and IFN- $\beta$ in LPS-induced THP-1 cells. THP-1 cells were pretreated with $50 \mu \mathrm{mol} / \mathrm{L}$ scropoliosides or catalpol for $1 \mathrm{~h}$ and then stimulated with LPS $(1 \mu \mathrm{g} / \mathrm{mL})$ for another 6 or $24 \mathrm{~h}$. (A) The secretion of IL-1 $\beta$ in the culture medium from the LPS-induced THP- 1 cells was measured using Abcam Human IL- $1 \beta$ ELISA kit; (B-D) The mRNA expression of IL-1 $\beta$, IL-8, and IFN- $\beta$ was measured using real-time RT-PCR. The data represent the mean values of more than three repeated experiments $\pm \mathrm{SD}$. \#\# $p<0.01 v$ s. the vehicle control, ${ }^{* *} p<0.01$ vs. LPS alone, ${ }^{*} p<0.05$ vs. LPS alone. 


\subsection{Activity of Arachidonic-Acid-Metabolizing Enzymes}

COX-2, which is induced by inflammatory cytokines, promotes prostaglandin synthesis and mediates reactions involved in pain, inflammation, and fever. To determine whether inflammatory factors induce COX-2 activity, we stimulated THP-1 cells with LPS for $24 \mathrm{~h}$. LPS upregulated COX-2 activity (Figure 5). Pretreatment with scrodentosides A and B inhibited COX-2 activity (Figure 5). We used the 15-LOX inhibitor screening assay kit to analyze inhibitory effects of these iridoids, and found that these iridoids did not inhibit 15-LOX activity (data not shown).

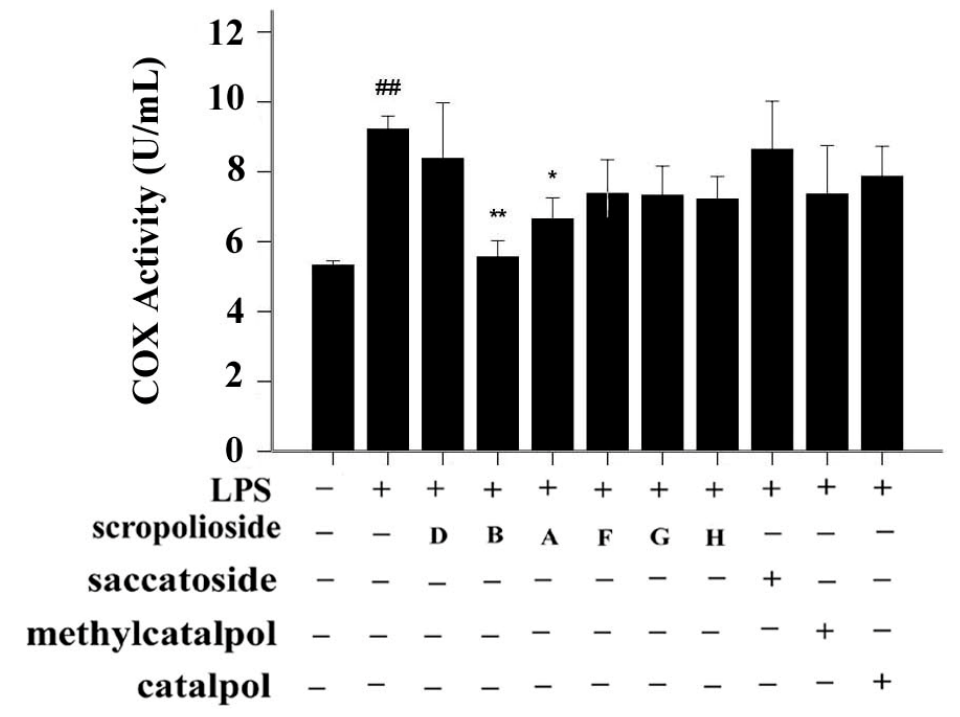

Figure 5. Effects of scropoliosides and catalpol on LPS-induced COX-2 activation. Cells were preincubated for $1 \mathrm{~h}$ with $50 \mu \mathrm{mol} / \mathrm{L}$ scropoliosides or catalpol and then stimulated with $1 \mu \mathrm{g} / \mathrm{mL}$ of LPS for $24 \mathrm{~h}$. The results shown are representative of three repeated experiments. Data are expressed as means $\pm \mathrm{SD}$. \#\# $p<0.01$ vs. the control, ${ }^{* *} p<0.01$ vs. LPS alone, ${ }^{*} p<0.05$ vs. LPS alone.

\subsection{Structure-Activity Relationship of the Eight Catalpol Derivatives and Catalpol}

Our results showed that all 6-O-substituted catalpol derivatives, whether rhamnopyranosylcatalpol or methyl-modified, exhibited higher inhibitory activities against NF- $\mathrm{kB}$ activation than catalpol did, indicating that compounds with low-polarity substituents at the 6-O position of catalpol displayed higher NF- $\mathrm{kB}$ inhibitory potency (Table 1). Moreover, the cinnamyl group-substituted positions $\mathrm{C}^{\prime \prime} 2-\mathrm{OH}, \mathrm{C}^{\prime \prime} 3-\mathrm{OH}$, and $\mathrm{C}^{\prime \prime} 4-\mathrm{OH}$ are associated with the antiinflammatory activity against NF- $\mathrm{kB}$ activation (Figure 1 and Table 1). For example, compounds with cinnamyl groups linked to $\mathrm{C}^{\prime \prime} 2-\mathrm{OH}$ (saccatoside and scrodentoside $\mathrm{H}$ ) exhibited higher inhibitory effects against NF- $\mathrm{KB}$ activation than those with cinnamyl groups lined to $\mathrm{C}^{\prime \prime} 3-\mathrm{OH}$ (scrodentosides A and D). Notably, scrodentoside A and D, containing cinnamyl groups linked to $\mathrm{C}^{\prime \prime} 3-\mathrm{OH}$, but not scrodentosides containing cinnamyl groups linked to $\mathrm{C}^{\prime \prime} 2-\mathrm{OH}$ or $\mathrm{C}^{\prime \prime} 4-\mathrm{OH}$, effectively prevented IL-1 $\beta$, IL-8, and IFN- $\beta$ mRNA expression (Table 1). Conversely, scropoliosides $B, F$, and G, containing a cinnamyl or feruloyl group at $C^{\prime \prime} 4-O H$, effectively blocked IL-1 $\beta$ secretion (Table 1). However, according to the structure-activity relationship, two cinnamyl groups should be included at $\mathrm{C}^{\prime \prime} 3-\mathrm{OH}$ and $\mathrm{C}^{\prime \prime} 4-\mathrm{OH}$ positions of scropolioside $\mathrm{B}$ for its COX-2 inhibitory activity (Table 1). 
Table 1. Inhibitory ratio of compounds for inflammatory indicators ( $\%$, each $n=3)$.

\begin{tabular}{|c|c|c|c|c|c|c|c|}
\hline Compounds & Structure & $\begin{array}{l}\text { Inhibitiory Ratio } \\
\text { of NF- } \kappa \text { B Activity }\end{array}$ & $\begin{array}{l}\text { Inhibitiory Ratio of } \\
\text { IL-1 } \beta \text { mRNA Expression }\end{array}$ & $\begin{array}{c}\text { Inhibitiory Ratio of } \\
\text { IL-1 } \beta \text { Protein Expression }\end{array}$ & $\begin{array}{l}\text { Inhibitiory Ratio of IL-8 } \\
\text { mRNA Expression }\end{array}$ & $\begin{array}{c}\text { Inhibitiory Ratio of } \\
\text { IFN- } \beta \text { mRNA Expression }\end{array}$ & $\begin{array}{l}\text { Inhibitiory Ratio } \\
\text { of COX-2 Activity }\end{array}$ \\
\hline Scropolioside B & & 49.1 & 79.5 & 58.8 & 54.6 & 35.9 & 32.3 \\
\hline Scropolioside D & & 40.9 & 45.1 & -0.1 & 29.4 & 16.5 & -1.9 \\
\hline Scrodentoside A & & 40.2 & 39.5 & 28.9 & 8.8 & 9.25 & 19.1 \\
\hline Scrodentoside F & & 41.9 & 31.6 & 44.5 & 10.8 & 5.6 & 10.2 \\
\hline Scrodentoside G & & 50.4 & 25 & 51.3 & 0.8 & 10.1 & 10.8 \\
\hline Scrodentoside $\mathrm{H}$ & & 52.8 & 26.8 & 24.1 & 19.3 & 13.5 & 12.1 \\
\hline
\end{tabular}


Table 1. Cont.

\begin{tabular}{|c|c|c|c|c|c|c|c|}
\hline Compounds & Structure & $\begin{array}{l}\text { Inhibitiory Ratio } \\
\text { of NF- } k \text { B Activity }\end{array}$ & $\begin{array}{l}\text { Inhibitiory Ratio of } \\
\text { IL-1 } \beta \text { mRNA Expression }\end{array}$ & $\begin{array}{l}\text { Inhibitiory Ratio of } \\
\text { IL-1 } \beta \text { Protein Expression }\end{array}$ & $\begin{array}{l}\text { Inhibitiory Ratio of IL-8 } \\
\text { mRNA Expression }\end{array}$ & $\begin{array}{c}\text { Inhibitiory Ratio of } \\
\text { IFN- } \beta \text { mRNA Expression }\end{array}$ & $\begin{array}{l}\text { Inhibitiory Ratio } \\
\text { of COX-2 Activity }\end{array}$ \\
\hline Saccatoside & & 58.1 & 24.9 & 17.9 & 31.7 & 11.2 & -5.1 \\
\hline Methylcatapol & & 59.2 & 9.6 & 51.3 & -2 & 8.9 & 10.4 \\
\hline Catalpol & & -2.3 & 9.8 & 25 & 19.9 & 34.7 & 4.2 \\
\hline
\end{tabular}




\subsection{Effect of Cinnamyl Moieties in Scropoliosides on Anti-inflammatory Activity}

Catalpol, aucubin, and genipin are the basic structural compounds of iridoids, which show weak antiinflammatory activity [16-18]. We recently showed that scropolioside B, a 6-O-substituted catalpol derivative, had higher antiinflammatory activity than catalpol did [9]. Scropoliosides contain one or more 6-O-substituted cinnamyl moieties, suggesting that the cinnamyl moiety is a critical structure that increases the antiinflammatory activity of catalpol derivatives. Ahmed et al. [19] also reported the antiinflammatory activity of scropolioside-D2 in a rat paw swelling experiment and thus concluded that compounds containing a cinnamyl moiety exhibit antiinflammatory activity. Similarly, other compounds with a cinnamyl moiety also exhibited an enhanced antiinflammatory activity [20-22]. In this study, scropoliosides with the cinnamyl moiety linked at different positions, namely $\mathrm{C}^{\prime \prime} 2-\mathrm{OH}, \mathrm{C}^{\prime \prime} 3-\mathrm{OH}$, and $\mathrm{C}^{\prime \prime} 4-\mathrm{OH}$, differently inhibited IL- $1 \beta$, IL-8, and IFN- $\beta$ mRNA expression, IL-1 $\beta$ secretion, and COX-2 activity (Table 1 ), demonstrating that the number and binding site of the cinnamyl moiety significantly affect antiinflammatory activity.

\subsection{NF-кB Activity, Cytokine Expression and Release, and the Inhibitory Effect of Scropoliosides}

Although all scropoliosides reduced NF- $\mathrm{KB}$ reporter activity to $40 \%-60 \%$, their ability to inhibit IL-1 $\beta$, IL-8, and IFN- $\beta$ mRNA expression, IL-1 $\beta$ secretion, and COX-2 activity differed. Possible reasons are as follows: (1) In addition to NF- $\mathrm{KB}$, the regulatory signals of IL-1 $\beta$ expression include C/EBP $\beta$ transcription factor and the p38/SAPK2 signaling pathway [23,24]; (2) IL-8 and IFN- $\beta$ mRNA are expressed later than IL-1 $\beta$ mRNA and can be activated by the IL- $1 \beta$ autocrine loop (Figure 3). Several studies have reported that the transcriptional upregulation of IL-8 is mediated by IL- $1 \beta$-stimulated activation of ERK1/2 and p38 $\alpha$ MAPK pathway $[25,26]$ and AP-1, ATF4, and NF- $\mathrm{KB}$ transcription factors $[27,28]$. Conversely, TLR4-induced IFN- $\beta$ mRNA expression is regulated through JNK-, p38-, TIRAP-, and PI3K-dependent and MyD88-independent pathways and IRF-3, STAT1, and XBP-1 transcription factors [29-32]; (3) The maturation and secretion of IL-1 $\beta$ requires inflammasomes and other signals $[9,33,34]$. Overall, all scropoliosides, except scropolioside $B$, may not completely prevent these signals.

\section{Experimental Section}

\subsection{General Information}

The NMR spectra were recorded on a Bruker AM-400 spectrometer (Bruker, Billerica, MA, USA) at $400 \mathrm{MHz}$ for ${ }^{1} \mathrm{H}$ and $100 \mathrm{MHz}$ for ${ }^{13} \mathrm{C}$ in $\mathrm{CD}_{3} \mathrm{OD}$. ESI-MS were obtained using a Thermo Finnigan LCQ Deca XP (Thermo Scientific, Waltham, MA, USA) equipped with an electrospray ionization source mass ion-trap. Silica gel (200 mesh to 300 mesh, Qingdao Haiyang Chemical Co., Ltd., Qingdao, China), C18 reversed-phase silica gel (150 to 200 mesh, Fuji Silysia Chemical, Ltd., Aichi, Japan), MCI gel (CHP20P, $75 \mu \mathrm{M}$ to $150 \mu \mathrm{M}$, Mitsubishi Chemical Industries, Ltd., Tokyo, Japan), and Sephadex LH-20 gel (Pharmacia Biotech AB, Uppsala, Sweden) were used for column chromatography (CC). High-performance liquid chromatography was performed on an Angilent 1200 HPLC System (Angilent, Santa Clara, CA, USA) apparatus with an Eclipse XDB-C18 column $(250 \times 9.4 \mathrm{~mm}, 5 \mu \mathrm{m})$.

The activity of the luciferase reporter gene was assayed using dual-luciferase reporter 1000 assay system and detected using a Varioskan Flash microplate spectrophotometer (Thermo Scientific). Quantitative PCR was performed using a 7500 Fast Real-Time PCR System (Life Technologies, Grand Island, NE, USA) according to manufacturer instructions. The cells were lysed in ice-cold RIPA buffer and sonicated using a JY92-2D ultrasonic homogenizer (Ningbo Scientz Biotechnology Co., Ltd, Zhejiang, China). Lysates were pre-cleared through centrifugation at $12,000 \mathrm{~g}$ for $10 \mathrm{~min}$ at $4{ }^{\circ} \mathrm{C}$. Aliquots of the cell lysate (50 or $100 \mu \mathrm{g}$ of each sample) were resolved using SDS-PAGE and blotted onto a nitrocellulose membrane (Pall China, Shanghai, China). The optical density (OD) of each 
well of ELISA was measured immediately by using a SpectraMax 190 Absorbance Microplate Reader (Molecular Devices, Sunnyvale, CA, USA).

\subsection{Cell Culture and Reagents}

Human embryonic kidney 293 (HEK293) and human acute monocytic leukemia cell line THP-1 cells were purchased from the Chinese Academy of Sciences (Shanghai, China). The HEK293 cells were cultured in 100-mm tissue culture dishes containing Dulbecco's modified Eagle's medium with $10 \%$ newborn calf serum (Gibco, Life Technologies) at $37^{\circ} \mathrm{C}$ in a humidified incubator in $5 \% \mathrm{CO}_{2}$ and 95\% air. The THP-1 cells were cultured in 100-mL flasks containing RPMI 1640 medium with $10 \%$ fetal bovine serum (Gibco) at $37{ }^{\circ} \mathrm{C}$ in a humidified incubator in $5 \% \mathrm{CO}_{2}$ and $95 \%$ air. During experiments, the cells were plated in 24-well plates or 30-mm tissue culture dishes and incubated for $16 \mathrm{~h}$ for qPCR determination, or $24 \mathrm{~h}$ for ELISA and activity assay. All tested scropoliosides were dissolved in dimethyl sulfoxide (DMSO) that its final concentration in the culture medium was less than $0.2 \%$.

\subsection{Extraction and Isolation of Iridoid Glycosides from S. dentata Royle ex Benth}

The isolation of scropoliosides A, B, and D was descibred in a previous study [35], which included the extraction and subsequent fractionation of the extract, evaporation of the $n$-butanol extract to dryness in vacuo, and silica-gel column chromatography elution of the resultant $n$-butanol fraction (572 g), using a gradient of EtOAc-EtOH (1:0-0:1) and finally EtOH to obtain fractions A-G. Fraction E was separated using MCI-gel column chromatography $\left(\mathrm{MeOH}-\mathrm{H}_{2} \mathrm{O}, 20: 80,25: 75,30: 70,35: 65\right.$, and 100:0) to obtain subfractions (scropoliosides A, $\mathrm{B}$, and $\mathrm{D}, 6-\mathrm{O}-\alpha-\mathrm{L}-\left(4^{\prime \prime}-\mathrm{O}\right.$-trans-p-coumaroyl) rhamnopyranosylcatalpol (named scropolioside $\mathrm{F}$ ), and 6-O- $\alpha$-L-( $\left(4^{\prime \prime}-O-\right.$ feruloyl) rhamnopyranosylcatalpol (named scropolioside G)). Fraction D2 was purified using Rp-18 (MeOH- $\left.\mathrm{H}_{2} \mathrm{O}, 20: 80-25: 75 \mathrm{v} / v\right)$ and sephadex LH-20 column shromatography $\left(\mathrm{MeOH}-\mathrm{H}_{2} \mathrm{O}, 1: 1 \mathrm{v} / v\right)$ to obtain 6-O-methylcatapol (14 mg). Fraction D4 was isolated using Rp-18 column chromatography $\left(\mathrm{MeOH}-\mathrm{H}_{2} \mathrm{O}, 20: 80-50: 50 \mathrm{v} / \mathrm{v}\right)$ and preparative HPLC on an Agilent Eclipse XDB-C18 column $(5 \mu \mathrm{mol} / \mathrm{L}, 9.4 \mathrm{~mm} \times 250 \mathrm{~mm})$, followed by elution with $\mathrm{CH} 3 \mathrm{CN}-\mathrm{H}_{2} \mathrm{O}(18: 82)$ to obtain scropoliosides $\mathrm{F}(44 \mathrm{mg})$ and $\mathrm{G}(19 \mathrm{mg})$. Using the same procedure, $6-\mathrm{O}-\alpha-\mathrm{L}-\left(2^{\prime \prime}-\mathrm{O}\right.$-feruloyl) rhamnopyranosylcatalpol (named scropolioside $\mathrm{H}, 200 \mathrm{mg}$ ) and saccatoside $(20 \mathrm{mg}$ ) were also obtained from fraction D4. Properties of scropolioside F, G, H, Saccatoside and 6-O-methylcatapol:

\subsubsection{6-O- $\alpha$-L-( $4^{\prime \prime}-O$-trans- $p$-Coumaroyl)rhamnopyranosylcatalpol (Scropolioside F)}

White amorphous powder. ESI-MS (pos.): $677[\mathrm{M}+\mathrm{Na}]^{+}$, ESI-MS (neg.): $653[\mathrm{M}-\mathrm{H}]^{-} .{ }^{1} \mathrm{H}-\mathrm{NMR}$ (400 MHz, CD $\left.{ }_{3} \mathrm{OD}\right): \delta_{\mathrm{H}} 6.38\left(2 \mathrm{H}, \mathrm{m}, \mathrm{H}-3 / \mathrm{H}_{-}{ }^{\prime \prime \prime}\right), 2.42(1 \mathrm{H}, \mathrm{m}, \mathrm{H}-5), 4.03(1 \mathrm{H}, \mathrm{d}, J=8.1 \mathrm{~Hz}, \mathrm{H}-6)$, $3.66(1 \mathrm{H}, \mathrm{br} \mathrm{s}, \mathrm{H}-7), 2.57(1 \mathrm{H}, \mathrm{dd}, J=8.3 / 8.9 \mathrm{~Hz}, \mathrm{H}-9), 4.16(1 \mathrm{H}, \mathrm{d}, J=13.1 \mathrm{~Hz}, \mathrm{H}-10 \mathrm{a}), 3.82(1 \mathrm{H}, \mathrm{d}$, $J=13.1 \mathrm{~Hz}, \mathrm{H}-10 \mathrm{~b}), 4.78\left(1 \mathrm{H}, \mathrm{d}, J=7.9 \mathrm{~Hz}, \mathrm{H}_{-1}^{\prime}\right), 3.41\left(1 \mathrm{H}, \mathrm{t}, J=9.0 \mathrm{~Hz}, \mathrm{H}-3^{\prime}\right), 3.63(1 \mathrm{H}, \mathrm{dd}, J=6.6 / 11.9$ $\left.\mathrm{Hz}, \mathrm{H}-6^{\prime} \mathrm{a}\right), 5.00\left(1 \mathrm{H}, \mathrm{br} \mathrm{s}, \mathrm{H}-1^{\prime \prime}\right), 1.17\left(3 \mathrm{H}, \mathrm{d}, J=6.2 \mathrm{~Hz}, \mathrm{H}-6^{\prime \prime}\right), 7.48\left(2 \mathrm{H}, \mathrm{d}, J=8.3 \mathrm{~Hz}, \mathrm{H}-2^{\prime \prime \prime}, 6^{\prime \prime \prime}\right)$, $6.81\left(3 \mathrm{H}, \mathrm{d}, J=8.3 \mathrm{~Hz}, \mathrm{H}-3^{\prime \prime \prime \prime}, 5^{\prime \prime \prime}\right), 7.66\left(1 \mathrm{H}, \mathrm{d}, J=15.9 \mathrm{~Hz}, \mathrm{H}-7^{\prime \prime \prime}\right), 5.05-5.12\left(3 \mathrm{H}, \mathrm{m}, \mathrm{H}-1, \mathrm{H}-4, \mathrm{H}-4^{\prime \prime}\right)$, 3.20-3.35 (4H, H-2', $\left.4^{\prime}, 5^{\prime}, 3^{\prime \prime}\right), 3.88-3.94\left(4 \mathrm{H}, \mathrm{H}-6^{\prime} \mathrm{b}, 2^{\prime \prime}, 5^{\prime \prime}\right) .{ }^{13} \mathrm{C}-\mathrm{NMR}\left(100 \mathrm{MHz}, \mathrm{CD}_{3} \mathrm{OD}\right): \delta_{\mathrm{C}} 95.3$ (C-1), 142.5 (C-3), 103.6 (C-4), 37.4 (C-5), 84.2 (C-6), 59.6 (C-7), 66.7 (C-8), 43.4 (C-9), 61.6 (C- 10), 99.8 (C-1'), $74.9\left(\mathrm{C}-2^{\prime}\right), 77.8\left(\mathrm{C}-3^{\prime}\right), 71.9\left(\mathrm{C}-4^{\prime}\right), 78.7\left(\mathrm{C}-5^{\prime}\right), 63.1\left(\mathrm{C}-6^{\prime}\right), 100.6\left(\mathrm{C}-1^{\prime \prime}\right), 72.6\left(\mathrm{C}-2^{\prime \prime}\right), 70.4\left(\mathrm{C}-3^{\prime \prime}\right)$, $75.4(\mathrm{C}-4 "), 68.4(\mathrm{C}-5 "), 18.0(\mathrm{C}-6 "), 127.3\left(\mathrm{C}-1^{\prime \prime \prime}\right), 131.4\left(2^{\prime \prime \prime}\right.$ and $\left.\mathrm{C}-6^{\prime \prime \prime}\right), 117.0\left(\mathrm{C}-3^{\prime \prime \prime}\right.$ and $\left.\mathrm{C}-5^{\prime \prime \prime}\right), 161.4$ $\left(\mathrm{C}-4^{\prime \prime \prime}\right), 147.1\left(\mathrm{C}-7^{\prime \prime \prime}\right), 115.2\left(\mathrm{C}-8^{\prime \prime \prime}\right), 169.1\left(\mathrm{C}-9^{\prime \prime \prime}\right)$.

\subsubsection{6-O- $\alpha$-L-(4"-O-Feruloyl)rhamnopyranosylcatalpol (Scropolioside G)}

White amorphous powder. ESI-MS (pos.): $707[\mathrm{M}+\mathrm{Na}]^{+}$, ESI-MS (neg.): $683[\mathrm{M}-\mathrm{H}]^{-} .{ }^{1} \mathrm{H}-\mathrm{NMR}$ $\left(400 \mathrm{MHz}, \mathrm{CD}_{3} \mathrm{OD}\right): \delta_{\mathrm{H}} 6.38(1 \mathrm{H}, \mathrm{br} \mathrm{d}, J=5.7 \mathrm{~Hz}, \mathrm{H}-3), 2.42(1 \mathrm{H}, \mathrm{m}, \mathrm{H}-5), 4.03(1 \mathrm{H}, \mathrm{d}, J=8.1 \mathrm{~Hz}$, H-6), $3.66(1 \mathrm{H}$, br s, H-7), $2.57(1 \mathrm{H}, \mathrm{dd}, J=8.0 / 9.0 \mathrm{~Hz}, \mathrm{H}-9), 4.16(1 \mathrm{H}, \mathrm{d}, J=13.1 \mathrm{~Hz}, \mathrm{H}-10 \mathrm{a}), 3.82$ $(1 \mathrm{H}, \mathrm{d}, J=13.1 \mathrm{~Hz}, \mathrm{H}-10 \mathrm{~b}), 4.78\left(1 \mathrm{H}, \mathrm{d}, J=7.9 \mathrm{~Hz}, \mathrm{H}-1^{\prime}\right), 3.41\left(1 \mathrm{H}, \mathrm{t}, J=9.0 \mathrm{~Hz}, \mathrm{H}-3^{\prime}\right), 3.63(1 \mathrm{H}, \mathrm{dd}$, 
$\left.J=6.6 / 11.8 \mathrm{~Hz}, \mathrm{H}-6^{\prime} \mathrm{a}\right), 4.99\left(1 \mathrm{H}, \mathrm{br} \mathrm{s}, \mathrm{H}-1^{\prime \prime}\right), 1.18\left(3 \mathrm{H}, \mathrm{d}, J=6.2 \mathrm{~Hz}, \mathrm{H}-6^{\prime \prime}\right), 7.21\left(1 \mathrm{H}, \mathrm{s}, \mathrm{H}-2^{\prime \prime \prime}\right), 6.82$ $\left(1 \mathrm{H}, \mathrm{d}, J=8.0 \mathrm{~Hz}, \mathrm{H}-5^{\prime \prime \prime}\right), 7.10\left(1 \mathrm{H}, \mathrm{d}, J=8.0 \mathrm{~Hz}, \mathrm{H}-6^{\prime \prime \prime}\right), 7.65\left(1 \mathrm{H}, \mathrm{d}, J=15.9 \mathrm{~Hz}, \mathrm{H}-7^{\prime \prime \prime}\right), 6.41(1 \mathrm{H}, \mathrm{d}$, $\left.J=15.9 \mathrm{~Hz}, \mathrm{H}-8^{\prime \prime \prime}\right), 5.05-5.10\left(3 \mathrm{H}, \mathrm{m}, \mathrm{H}-1, \mathrm{H}-4, \mathrm{H}-4^{\prime \prime}\right), 3.20-3.35\left(4 \mathrm{H}, \mathrm{H}-2^{\prime}, 4^{\prime}, 5^{\prime}, 3^{\prime \prime}\right), 3.86-3.94(4 \mathrm{H}$,

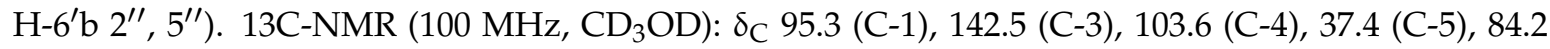
(C-6), 59.6 (C-7), 66.7 (C-8), 43.4 (C-9), 61.6 (C- 10), 99.8 (C-1'), $74.9\left(\mathrm{C}-2^{\prime}\right), 77.8$ (C-3'), $71.9\left(\mathrm{C}-4^{\prime}\right), 78.7$ (C-5'), $63.1\left(\mathrm{C}-6^{\prime}\right), 100.6\left(\mathrm{C}-1^{\prime \prime}\right), 72.6$ (C-2"), $70.4\left(\mathrm{C}-3^{\prime \prime}\right), 75.4\left(\mathrm{C}-4^{\prime \prime}\right), 68.4$ (C-5"), $18.0\left(\mathrm{C}-6^{\prime \prime}\right), 127.9\left(\mathrm{C}-1^{\prime \prime \prime}\right)$, $111.9\left(\mathrm{C}-2^{\prime \prime \prime}\right), 150.8\left(\mathrm{C}-3^{\prime \prime \prime}\right), 149.5\left(\mathrm{C}-4^{\prime \prime \prime}\right), 115.6\left(\mathrm{C}-5^{\prime \prime \prime}\right), 124.3\left(\mathrm{C}-6^{\prime \prime \prime}\right), 147.3\left(\mathrm{C}-7^{\prime \prime \prime}\right), 116.6\left(\mathrm{C}-8^{\prime \prime \prime}\right), 169.0$ $\left(\mathrm{C}-9^{\prime \prime \prime}\right), 56.6(\mathrm{OMe})$.

\subsubsection{6-O- $\alpha$-L-(2"-O-Feruloyl)rhamnopyranosylcatalpol (Scropolioside H)}

White amorphous powder. ESI-MS (pos.): $707[\mathrm{M}+\mathrm{Na}]^{+}$, ESI-MS (neg.): $683[\mathrm{M}-\mathrm{H}]^{-} .{ }^{1} \mathrm{H}-\mathrm{NMR}$ (400 MHz, CD $\left.{ }_{3} \mathrm{OD}\right): \delta \mathrm{H} 6.39(1 \mathrm{H}, \mathrm{dd}, J=6.0 / 1.7 \mathrm{~Hz}, \mathrm{H}-3), 2.45(1 \mathrm{H}, \mathrm{m}, \mathrm{H}-5), 4.04(1 \mathrm{H}, \mathrm{d}, J=8.2 \mathrm{~Hz}$, H-6), 3.67 (1H, br s, H-7), 2.59 (1H, dd, $J=7.8 / 8.9 \mathrm{~Hz}, \mathrm{H}-9), 4.17(1 \mathrm{H}, \mathrm{d}, J=13.1 \mathrm{~Hz}, \mathrm{H}-10 \mathrm{a}), 3.82$ $(1 \mathrm{H}, \mathrm{d}, J=13.1 \mathrm{~Hz}, \mathrm{H}-10 \mathrm{~b}), 4.79\left(1 \mathrm{H}, \mathrm{d}, J=7.9 \mathrm{~Hz}, \mathrm{H}-1^{\prime}\right), 3.42\left(1 \mathrm{H}, \mathrm{t}, J=9.0 \mathrm{~Hz}, \mathrm{H}-3^{\prime}\right), 3.64(1 \mathrm{H}$, $\left.\mathrm{dd}, J=6.7 / 11.9 \mathrm{~Hz}, \mathrm{H}-6^{\prime} \mathrm{a}\right), 5.05\left(1 \mathrm{H}, \mathrm{d}, J=1.3 \mathrm{~Hz}, \mathrm{H}-1^{\prime \prime}\right), 5.17\left(1 \mathrm{H}, \mathrm{dd}, J=3.4 / 1.3 \mathrm{~Hz}, \mathrm{H}-2^{\prime \prime}\right), 3.95$ $\left(1 \mathrm{H}, \mathrm{dd}, J=3.4 / 9.6 \mathrm{~Hz}, \mathrm{H}-3^{\prime \prime}\right), 3.51\left(1 \mathrm{H}, \mathrm{t}, J=9.6 \mathrm{~Hz}, \mathrm{H}-4^{\prime \prime}\right), 3.77\left(1 \mathrm{H}, \mathrm{dd}, J=9.6 / 6.2 \mathrm{~Hz}, \mathrm{H}-5^{\prime \prime}\right)$, $1.33\left(3 \mathrm{H}, \mathrm{d}, J=6.2 \mathrm{~Hz}, \mathrm{H}-6^{\prime \prime}\right), 7.24\left(1 \mathrm{H}, \mathrm{d}, J=1.5 \mathrm{~Hz}, \mathrm{H}-2^{\prime \prime \prime}\right), 6.84\left(1 \mathrm{H}, \mathrm{d}, J=8.3 \mathrm{~Hz}, \mathrm{H}-5^{\prime \prime \prime}\right), 7.11$ $\left(1 \mathrm{H}, \mathrm{dd}, J=8.3 / 1.5 \mathrm{~Hz}, \mathrm{H}-6^{\prime \prime \prime}\right), 7.68\left(1 \mathrm{H}, \mathrm{d}, J=15.9 \mathrm{~Hz}, \mathrm{H}-7^{\prime \prime \prime}\right), 6.46\left(1 \mathrm{H}, \mathrm{d}, J=15.9 \mathrm{~Hz}, \mathrm{H}-8^{\prime \prime \prime}\right), 3.92$ (3H, s, OMe); ${ }^{13} \mathrm{C}-\mathrm{NMR}\left(100 \mathrm{MHz}, \mathrm{CD}_{3} \mathrm{OD}\right): \delta_{\mathrm{C}} 95.3$ (C-1), 142.4 (C-3), 103.6 (C-4), 37.4 (C-5), 84.5 (C-6), 59.6 (C-7), 66.7 (C-8), 43.4 (C-9), 61.6 (C- 10), 99.8 (C-1'), $75.0\left(\mathrm{C}-2^{\prime}\right), 77.8$ (C-3'), 71.9 ( C-4' $), 78.7$ (C-5'), 63.1 (C-6'), 97.8 (C-1"), 74.4 (C-2"), 70.7 (C-3"), 74.3 (C-4"), 70.4 (C-5"), 18.2 (C-6"), 127.9 (C-1"'), $111.8\left(\mathrm{C}-2^{\prime \prime \prime}\right), 150.9\left(\mathrm{C}-3^{\prime \prime \prime}\right), 149.5\left(\mathrm{C}-4^{\prime \prime \prime}\right), 115.4\left(\mathrm{C}-5^{\prime \prime \prime}\right), 124.5\left(\mathrm{C}-6^{\prime \prime \prime}\right), 147.6\left(\mathrm{C}-7^{\prime \prime \prime}\right), 116.6\left(\mathrm{C}-8^{\prime \prime \prime}\right), 168.8$ $\left(\mathrm{C}-9^{\prime \prime \prime}\right), 56.6(\mathrm{OMe})$.

\subsubsection{Saccatoside}

White amorphous powder. ESI-MS (pos.): $661[\mathrm{M}+\mathrm{Na}]^{+}$, ESI-MS (neg.): $637[\mathrm{M}-\mathrm{H}]^{-} .{ }^{1} \mathrm{H}-\mathrm{NMR}$ $\left(400 \mathrm{MHz}, \mathrm{CD}_{3} \mathrm{OD}\right): \delta_{\mathrm{H}} 6.38(1 \mathrm{H}, \mathrm{dd}, J=6.0 / 1.7 \mathrm{~Hz}, \mathrm{H}-3), 2.43(1 \mathrm{H}, \mathrm{m}, \mathrm{H}-5), 4.03(1 \mathrm{H}, \mathrm{d}, J=8.2 \mathrm{~Hz}$, H-6), $3.65(1 \mathrm{H}, \mathrm{br} \mathrm{s}, \mathrm{H}-7), 2.57(1 \mathrm{H}, \mathrm{dd}, J=7.7 / 9.7 \mathrm{~Hz}, \mathrm{H}-9), 4.15(1 \mathrm{H}, \mathrm{d}, J=13.1 \mathrm{~Hz}, \mathrm{H}-10 \mathrm{a}), 3.80$ $(1 \mathrm{H}, \mathrm{d}, J=13.1 \mathrm{~Hz}, \mathrm{H}-10 \mathrm{~b}), 4.77\left(1 \mathrm{H}, \mathrm{d}, J=7.9 \mathrm{~Hz}, \mathrm{H}-1^{\prime}\right), 3.40\left(1 \mathrm{H}, \mathrm{t}, J=9.0 \mathrm{~Hz}, \mathrm{H}-3^{\prime}\right), 3.62(1 \mathrm{H}, \mathrm{dd}$, $\left.J=6.7 / 11.9 \mathrm{~Hz}, \mathrm{H}-6^{\prime} \mathrm{a}\right), 5.02\left(1 \mathrm{H}, \mathrm{d}, J=1.5 \mathrm{~Hz}, \mathrm{H}-1^{\prime \prime}\right), 5.17\left(1 \mathrm{H}, \mathrm{dd}, J=3.5 / 1.5 \mathrm{~Hz}, \mathrm{H}-2^{\prime \prime}\right), 3.93(1 \mathrm{H}$, $\left.\mathrm{dd}, J=3.5 / 9.6 \mathrm{~Hz}, \mathrm{H}-3^{\prime \prime}\right), 3.49\left(1 \mathrm{H}, \mathrm{t}, J=9.6 \mathrm{~Hz}, \mathrm{H}-4^{\prime \prime}\right), 3.75\left(1 \mathrm{H}, \mathrm{dd}, J=9.6 / 6.2 \mathrm{~Hz}, \mathrm{H}-5^{\prime \prime}\right), 1.31(3 \mathrm{H}$, $\left.\mathrm{d}, J=6.2 \mathrm{~Hz}, \mathrm{H}-6^{\prime \prime}\right), 7.48\left(2 \mathrm{H}, \mathrm{d}, J=8.6 \mathrm{~Hz}, \mathrm{H}-2^{\prime \prime \prime}, 6^{\prime \prime \prime}\right), 6.81\left(2 \mathrm{H}, \mathrm{d}, J=8.6 \mathrm{~Hz}, \mathrm{H}-3^{\prime \prime \prime}, 5^{\prime \prime \prime}\right), 7.67(1 \mathrm{H}, \mathrm{d}$, $\left.J=15.9 \mathrm{~Hz}, \mathrm{H}-7^{\prime \prime \prime}\right), 6.40\left(1 \mathrm{H}, \mathrm{d}, J=15.9 \mathrm{~Hz}, \mathrm{H}-8^{\prime \prime \prime}\right) ;{ }^{13} \mathrm{C}-\mathrm{NMR}\left(100 \mathrm{MHz}, \mathrm{CD}_{3} \mathrm{OD}\right): \delta_{\mathrm{C}} 95.3(\mathrm{C}-1), 142.4$ (C-3), 103.6 (C-4), 37.4 (C-5), 84.5 (C-6), 59.6 (C-7), 66.7 (C-8), 43.4 (C-9), 61.6 (C- 10), 99.8 (C-1'), 75.0 (C-2'), 77.8 (C-3'), 71.9 ( C-4'), 78.8 (C-5'), 63.1 (C-6'), 97.9 (C-1"), 74.4 (C-2"), 70.7 (C-3"), 74.3 (C-4"), 70.4 (C-5"), 18.2 (C-6"), $127.3\left(\mathrm{C}-1^{\prime \prime \prime}\right), 131.4\left(\mathrm{C}-2^{\prime \prime \prime}\right), 117.0\left(\mathrm{C}-3^{\prime \prime \prime}\right), 161.5\left(\mathrm{C}-4^{\prime \prime \prime}\right), 117.0\left(\mathrm{C}-5^{\prime \prime \prime}\right), 131.4$ $\left(\mathrm{C}-6^{\prime \prime \prime}\right), 147.3\left(\mathrm{C}-7^{\prime \prime \prime}\right), 115.1\left(\mathrm{C}-8^{\prime \prime \prime}\right), 168.8\left(\mathrm{C}-9^{\prime \prime \prime}\right)$.

\subsubsection{6-O-Methylcatapol}

White amorphous powder. ESI-MS (pos.): 399 [M + Na] $]^{+}$, ESI-MS (neg.): $435\left[\mathrm{M}+\mathrm{CH}_{3} \mathrm{COO}-\right]^{-}$. ${ }^{1} \mathrm{H}-\mathrm{NMR}\left(400 \mathrm{MHz}, \mathrm{CD}_{3} \mathrm{OD}\right): \delta_{\mathrm{H}} 5.47(1 \mathrm{H}, \mathrm{d}, J=9.6 \mathrm{~Hz}, \mathrm{H}-1), 6.45(1 \mathrm{H}, \mathrm{dd}, J=1.8 / 6.0 \mathrm{~Hz}, \mathrm{H}-3), 5.10$ $(1 \mathrm{H}, \mathrm{dd}, J=6.0 / 4.6 \mathrm{~Hz}, \mathrm{H}-4), 2.68(1 \mathrm{H}, \mathrm{m}, \mathrm{H}-5), 3.45(1 \mathrm{H}, \mathrm{br} \mathrm{d}, J=8.1 \mathrm{~Hz}, \mathrm{H}-6), 3.71(1 \mathrm{H}, \mathrm{br} \mathrm{s}, \mathrm{H}-7)$, $2.78(1 \mathrm{H}, \mathrm{dd}, J=7.8 / 9.6 \mathrm{~Hz}, \mathrm{H}-9), 4.46(1 \mathrm{H}, \mathrm{d}, J=13.1 \mathrm{~Hz}, \mathrm{H}-10 \mathrm{a}), 4.51(1 \mathrm{H}, \mathrm{d}, J=13.1 \mathrm{~Hz}, \mathrm{H}-10 \mathrm{~b}), 3.36$ $(3 \mathrm{H}, \mathrm{s}, \mathrm{OCH} 3), 5.55\left(1 \mathrm{H}, \mathrm{d}, J=7.9 \mathrm{~Hz}, \mathrm{H}-1^{\prime}\right), 4.15\left(1 \mathrm{H}, \mathrm{dd}, J=7.9 / 8.9 \mathrm{~Hz}, \mathrm{H}-2^{\prime}\right), 4.30(1 \mathrm{H}, \mathrm{t}, J=8.9 \mathrm{~Hz}$, H-3' $), 4.20\left(1 \mathrm{H}, \mathrm{t}, J=8.9 \mathrm{~Hz}, \mathrm{H}-4^{\prime}\right), 4.04\left(1 \mathrm{H}, \mathrm{ddd}, J=2.0 / 5.8 / 8.9 \mathrm{~Hz}, \mathrm{H}-5^{\prime}\right), 4.34(1 \mathrm{H}, \mathrm{dd}, J=5.8 / 11.7$ $\left.\mathrm{Hz}, \mathrm{H}-6^{\prime} \mathrm{a}\right), 4.57\left(1 \mathrm{H}, \mathrm{dd}, J=2.0 / 11.7 \mathrm{~Hz}, \mathrm{H}-6^{\prime} \mathrm{b}\right), 3.36\left(3 \mathrm{H}, \mathrm{s}, \mathrm{OCH}_{3}\right) .{ }^{13} \mathrm{C}-\mathrm{NMR}\left(100 \mathrm{MHz}, \mathrm{CD}_{3} \mathrm{OD}\right)$ : $\delta_{\mathrm{C}} 95.2$ (C-1), 141.6 (C-3), 103.9 (C-4), 37.1 (C-5), 87.9 (C-6), 58.3 (C-7), 66.6 (C-8), 43.5 (C-9), 60.7 (C-10), $100.5\left(\mathrm{C}-1^{\prime}\right), 75.4\left(\mathrm{C}-2^{\prime}\right), 79.4\left(\mathrm{C}-3^{\prime}\right), 71.9\left(\mathrm{C}-4^{\prime}\right), 78.7\left(\mathrm{C}-5^{\prime}\right), 63.1\left(\mathrm{C}-6^{\prime}\right), 57.8(\mathrm{OMe})$. 


\subsection{Luciferase Assay}

To assay NF-kB promoter activity, HEK-293 cells were transiently transfected with a luciferase reporter gene. pNF-кB-TA-Luc was purchased from Stratagene (La Jolla, CA USA). The cells were plated 1 day prior to transfection to obtain an approximately $80 \%$ confluence on the day of the transfection, when the DNA was diluted to $2 \mu \mathrm{g} / 100 \mu \mathrm{L}$ of serum-free medium, and an appropriate amount of FuGENE HD transfection reagent (Promega, Madison, MI, USA) was added to achieve the optimal reagent-to-DNA ratio. The mixture was incubated for $0-15 \mathrm{~min}$, and $100 \mu \mathrm{L}$ of the mixture was added to each well for transfecting the cells. The cells were transfected for $5 \mathrm{~h}$, and the mixture was then replaced with fresh media. One hour after the transfection, TNF- $\alpha$ was added to the cells, and the cells were incubated for $16 \mathrm{~h}$. Luciferase activity was measured in the cell lysates using the Promega luciferase assay system according to the manufacturer's instructions (Promega).

\subsection{Quantitative Real-Time PCR}

Total RNA was extracted using TRIzol reagent (Life Technologies) according to the manufacturer's instructions. Real-time PCR amplification and detection were performed using the SYBR Green qPCR SuperMix-UDG with ROX (Life Technologies) in a fluorescence thermal cycler (StepOne real-time PCR system, Life Technologies) according to the manufacturer's protocol. Relative mRNA expression levels were calculated by following the $\Delta \Delta \mathrm{C}$ method, using the following primers: GAPDH, IL-1 $\beta$, IL-8, and IFN- $\gamma$ (Table 2). All amplifications were conducted within the linear range of the assay and normalized to respective GAPDH levels by using SPSS Version 18.0 (SPSS Institute, Inc., Chicago, IL, USA).

Table 2. Primer sequences of the genes tested in this study.

\begin{tabular}{ccc}
\hline Gene & Direction & Primer Sequences \\
\hline \multirow{2}{*}{ IL-1 $\beta$} & Forward & 5-AAACAGATGAAGTGCTCCTTCCAGG-3 \\
& Reverse & 5-TGGAGAACACCACTTGTTGCTCCA-3 \\
IL-8 & Forward & 5-ATGGCTGCTGAACCAGTAGA-3 \\
& Reverse & 5-CTAGTCTTCGTTTTGAACAG-3 \\
IFN- $\beta$ & Forward & 5-GCCTCAAGGACAGGATGAAC-3 \\
& Reverse & 5-AGCCAGGAGGTTCTCAACAA-3 \\
GAPDH & Forward & 5-AGAAGGCTGGGGCTCATTTG-3 \\
& Reverse & 5-AGGGGCCATCCACAGTCTTC-3 \\
\hline
\end{tabular}

\subsection{ELISA}

Culture media from the control and treated cells were collected, centrifuged, and stored at $-80{ }^{\circ} \mathrm{C}$ until further analysis. IL-1 $\beta$ was measured using the Abcam Human ELISA kit (Abcam, Cambridge, UK) according to the manufacturer's instructions. IFN- $\beta$ was measured using the Verikine Human IFN Beta ELISA kit (PBL Assay Science, Piscataway, NJ, USA) according to the manufacturer's instructions. The standard or sample was added to each well, and the wells were incubated for $2.5 \mathrm{~h}$ at room temperature. The prepared biotin antibody was then added to each well, followed by incubation for $1 \mathrm{~h}$ at room temperature. Streptavidin solution was added, and the plates were incubated for $45 \mathrm{~min}$ at room temperature. Finally, TMB One-Step development solution was added to each well, and the plates were incubated for $30 \mathrm{~min}$ at room temperature. A stop solution was then added to each well, and the absorbance at $450 \mathrm{~nm}$ was recorded immediately.

\subsection{Screening Assay for 15-Lipoxygenase Inhibitor}

Lipoxygenase (LOX) inhibitory activity was measured using a Cayman lipoxygenase inhibitor screening assay kit (Cayman Chemical Company, Ann Arbor, MI, USA) according to the manufacturer's instructions. The assay buffer was added to the blank and positive control wells and 15-LOX was added to the positive control wells, wells with 100\% initial activity, and inhibitor 
wells. The solvent was added to the wells with $100 \%$ initial activity, and the inhibitor was added to the inhibitor wells. The substrate was then added to all the wells, and the wells were incubated for $5 \mathrm{~min}$. Finally, the chromogen was added to each well, and the wells were incubated for $5 \mathrm{~min}$ to stop enzyme catalysis and develop the reaction. The absorbance at 490-500 nm was recorded.

\subsection{COX-2 Activity Assay}

COX-2 activity was measured using a Cayman COX activity assay kit (Cayman Chemical Company) according to the manufacturer's instructions. The assay buffer, heme, standard, inhibitor, inactive sample, and sample were added to appropriate wells, and the wells were incubated for $5 \mathrm{~min}$ at $25{ }^{\circ} \mathrm{C}$. The colorimetric substrate was then added to all of the wells. Finally, arachidonic acid solution was added to the wells, and the wells were incubated for $5 \mathrm{~min}$ at $25^{\circ} \mathrm{C}$. The absorbance at $590 \mathrm{~nm}$ was recorded.

\subsection{Data Analysis}

Each experiment was performed at least 3 times. The results were presented as means \pm standard error of mean (SD). All data were analyzed using SPSS software, and a post hoc test in one-way ANOVA was used to determine the statistical significance of differences between the means. Differences were considered statistically significant when $p<0.05$.

\section{Conclusions}

Our results show that scropoliosides differently inhibit the expression of various cytokines, IL-1 $\beta$ maturation and secretion, and COX-2 activity because of the different positions of linkage of the 6-O-substituted cinnamyl moieties, at $\mathrm{C}^{\prime \prime} 2-\mathrm{OH}, \mathrm{C}^{\prime \prime} 3-\mathrm{OH}$, or $\mathrm{C}^{\prime \prime} 4-\mathrm{OH}$. Moreover, the number of cinnamon moieties is closely related to the enhancement of anti-inflammatory activity. Among these compounds, scropolioside B has the strongest anti-inflammatory effects.

Acknowledgments: This work was supported by grants from the National Natural Science Foundation of China (81173518 and 81274130), the Shanghai 085 Project of Higher Education Connotation Construction of China (085ZY1202), and the Funding Scheme for Training Young Teachers in Shanghai Colleges of China (No. ZZszy13057).

Author Contributions: J.-W.X. and Y. L. designed the study. T. Z. performed experiments on pharmacology. L. Z. executed experiments on plant compound extraction, purification and structure determination. S. L. and F. Q. participated in the assistant experiments. J.-W. X. and Y. L. provided experimental expenditures. J.-W. X., T. Z., and L. Z. drafted articles. All the people read the article and put forward suggestions.

Conflicts of Interest: The authors declare no conflict of interest.

\section{Abbreviations}

AGE: advanced glycation endproducts; COX-2: cyclooxygenase-2; DMSO: dimethyl sulfoxide; GAPDH: glyceraldehyde 3-phosphate dehydrogenase; HEK293: Human embryonic kidney 293 cell line; IFN- $\beta$ : interferon- $\beta$; IL-1 $\beta$ : interleukin- $\beta \beta$; LPS: Lipopolysaccharides; LRR: Leucine-rich repeat protein; 15-LOX: 15-lipoxygenase; MCP-1: monocyte chemotactic protein-1; NACHT: neuronal apoptosis inhibitor protein; NF-kB: nuclear factor (NF)-KB; NLRP3: NACHT, LRR and PYD domains-containing protein 3; PGE $_{2}$ : prostaglandin E2; PYD: protein pyrin domain; THP-1 cell: Human acute monocytic leukemia cell line; TNF- $\alpha$ : tumor necrosis factor- $\alpha$.

\section{References}

1. Viljoen, A.; Mncwangi, N.; Vermaak, I. Anti-inflammatory iridoids of botanical origin. Curr. Med. Chem. 2012, 19, 2104-2127. [CrossRef] [PubMed]

2. Tundis, R.; Loizzo, M.R.; Menichini, F.; Statti, G.A.; Menichini, F. Biological and pharmacological activities of iridoids: Recent developments. Mini Rev. Med. Chem. 2008, 8, 399-420. [CrossRef] [PubMed] 
3. Giner, R.M.; Villalba, M.L.; Recio, M.C.; Máñez, S.; Cerdá-Nicolás, M.; Ríos, J. Anti-inflammatory glycoterpenoids from Scrophularia auriculata. Eur. J. Pharmacol. 2000, 389, 243-252. [CrossRef]

4. Dinda, B.; Debnath, S.; Banik, R. Naturally occurring iridoids and secoiridoids. An updated review, part 4. Chem. Pharm. Bull. 2011, 59, 803-833. [CrossRef] [PubMed]

5. Zhang, L.; Feng, L.; Jia, Q.; Xu, J.; Wang, R.; Wang, Z.; Wu, Y.; Li, Y. Effects of $\beta$-glucosidase hydrolyzed products of harpagide and harpagoside on cyclooxygenase-2 (COX-2) in vitro. Bioorg. Med. Chem. 2011, 19, 4882-4886. [CrossRef] [PubMed]

6. Park, K.S.; Kim, B.H.; Chang, I.M. Inhibitory Potencies of Several Iridoids on Cyclooxygenase-1, Cyclooxygnase-2 Enzymes Activities, Tumor Necrosis factor- $\alpha$ and Nitric Oxide Production in Vitro. Evid. Based Complement. Altern. Med. 2010, 7, 41-45. [CrossRef] [PubMed]

7. Choi, H.J.; Jang, H.J.; Chung, T.W.; Jeong, S.I.; Cha, J.; Choi, J.Y.; Han, C.W.; Jang, Y.S.; Joo, M.; Jeong, H.S.; et al. Catalpol suppresses advanced glycation end-products-induced inflammatory responses through inhibition of reactive oxygen species in human monocytic THP-1 cells. Fitoterapia 2013, 86, 19-28. [CrossRef] [PubMed]

8. Fu, K.; Piao, T.; Wang, M.; Zhang, J.; Jiang, J.; Wang, X.; Liu, H. Protective effect of catalpol on lipopolysaccharide-induced acute lung injury in mice. Int. Immunopharmacol. 2014, 23, 400-406. [CrossRef] [PubMed]

9. Zhu, T.; Zhang, L.; Ling, S.; Duan, J.; Qian, F.; Li, Y.; Xu, J.W. Scropolioside B inhibits IL-1 $\beta$ and cytokines expression through NF-kB and inflammasome NLRP3 pathways. Mediat. Inflamm. 2014, 2014, 819053. [CrossRef] [PubMed]

10. Bas, E.; Recio, M.C.; Máñez, S.; Giner, R.M.; Escandell, J.M.; López-Ginés, C.; Ríos, J.L. New insight into the inhibition of the inflammatory response to experimental delayed-type hypersensitivity reactions in mice by scropolioside A. Eur. J. Pharmacol. 2007, 555, 199-210. [CrossRef] [PubMed]

11. Helfrich, E.; Rimpler, H. Iridoid glycosides and phenolic glycosides from Holmskioldia sanguinea. Phytochemistry 1999, 50, 619-627. [CrossRef]

12. Warashina, T.; Miyase, T.; Ueno, A. Iridoid glycosides from Verbascum thapsus L. Chem. Pharm. Bull. 1991, 39, 3261-3264. [CrossRef]

13. Otsuka, H.; Kubo, N.; Sasaki, Y.; Yamasaki, K.; Takeda, Y.; Seki, T. Iridoid diglycoside monoacyl esters from stems of Premna japonica. Phytochemistry 1991, 30, 1917-1920. [CrossRef]

14. Otsuka, H.; Sasaki, Y.; Yamasaki, K.; Takeda, Y.; Seki, T. Iridoid Diglycoside Monoacyl Esters from the Leaves of Premna japonica. J. Nat. Prod. 1990, 53, 107-111. [CrossRef]

15. Zhang, W.J.; Liu, Y.Q.; Li, X.C.; Pu, X.Y.; Jin, Y.Q.; Yang, C.R. Chemical constituents from Scrophularia ningpoensis. Acta Bot. Yunnanica 1994, 16, 407-412.

16. Recio, M.C.; Giner, R.M.; Máñez, S.; Ríos, J.L. Structural considerations on the iridoids as anti-inflammatory agents. Planta Med. 1994, 60, 232-234. [CrossRef] [PubMed]

17. Park, K.S.; Chang, I.M. Anti-inflammatory activity of aucubin by inhibition of tumor necrosis factor-alpha production in RAW 264.7 cells. Planta Med. 2004, 70, 778-779. [CrossRef] [PubMed]

18. Koo, H.J.; Lim, K.H.; Jung, H.J.; Park, E.H. Anti-inflammatory evaluation of gardenia extract, geniposide and genipin. J. Ethnopharmacol. 2006, 103, 496-500. [CrossRef] [PubMed]

19. Ahmed, B.; Al-Rehaily, A.J.; Al-Howiriny, T.A.; El-Sayed, K.A.; Ahmad, M.S. Scropolioside-D2 and harpagoside-B: Two new iridoid glycosides from Scrophularia deserti and their antidiabetic and antiinflammatory activity. Biol. Pharm. Bull. 2003, 26, 462-467. [CrossRef] [PubMed]

20. Cartron, E.; Carbonneau, M.A.; Fouret, G.; Descomps, B.; Léger, C.L. Specific antioxidant activity of caffeoyl derivatives and other natural phenolic compounds: LDL protection against oxidation and decrease in the proinflammatory lysophosphatidylcholine production. J. Nat. Prod. 2001, 64, 480-486. [CrossRef] [PubMed]

21. De Cássia da Silveira E Sá, R.; Andrade, L.N.; Dos Reis Barreto de Oliveira, R.; de Sousa, D.P. A review on anti-inflammatory activity of phenylpropanoids found in essential oils. Molecules 2014, 19, 1459-1480. [CrossRef] [PubMed]

22. Kurokawa, M.; Brown, J.; Kagawa, Y.; Shiraki, K. Cytokine-regulatory activity and therapeutic efficacy of cinnamyl derivatives in endotoxin shock. Eur. J. Pharmacol. 2003, 474, 283-293. [CrossRef] 
23. Ropert, C.; Closel, M.; Chaves, A.C.; Gazzinelli, R.T. Inhibition of a p38/stress-activated protein kinase-2-dependent phosphatase restores function of IL-1 receptor-associate kinase-1 and reverses Toll-like receptor 2- and 4-dependent tolerance of macrophages. J. Immunol. 2003, 171, 1456-1465. [CrossRef] [PubMed]

24. Basak, C.; Pathak, S.K.; Bhattacharyya, A.; Mandal, D.; Pathak, S.; Kundu, M. NF-kB- and $\mathrm{C} / \mathrm{EBP} \beta$-driven interleukin-1beta gene expression and PAK1-mediated caspase-1 activation play essential roles in interleukin-1beta release from Helicobacter pylori lipopolysaccharide-stimulated macrophages. J. Biol. Chem. 2005, 280, 4279-4288. [CrossRef] [PubMed]

25. Yang, H.T.; Cohen, P.; Rousseau, S. IL- $1 \beta$-stimulated activation of ERK $1 / 2$ and p38 $\alpha$ MAPK mediates the transcriptional up-regulation of IL-6, IL-8 and GRO- $\alpha$ in HeLa cells. Cell Signal. 2008, 20, 375-380. [CrossRef] [PubMed]

26. Liu, X.; Ye, F.; Xiong, H.; Hu, D.; Limb, G.A.; Xie, T.; Peng, L.; Yang, W.; Sun, Y.; Zhou, M.; et al. IL-1 $\beta$ Upregulates IL-8 Production in Human Müller Cells through Activation of the p38 MAPK and ERK1/2 Signaling Pathways. Inflammation 2014, 37, 1486-1495. [CrossRef] [PubMed]

27. Tanaka, C.; Kamata, H.; Takeshita, H.; Yagisawa, H.; Hirata, H. Redox regulation of lipopolysaccharide (LPS)-induced interleukin-8 (IL-8) gene expression mediated by NF kappa B and AP-1 in human astrocytoma U373 cells. Biochem. Biophys. Res. Commun. 1997, 232, 568-573. [CrossRef] [PubMed]

28. Zhang, C.; Bai, N.; Chang, A.; Zhang, Z.; Yin, J.; Shen, W.; Tian, Y.; Xiang, R.; Liu, C. ATF4 is directly recruited by TLR4 signaling and positively regulates TLR4-trigged cytokine production in human monocytes. Cell. Mol. Immunol. 2013, 10, 84-94. [CrossRef] [PubMed]

29. Toshchakov, V.; Jones, B.W.; Perera, P.Y.; Thomas, K.; Cody, M.J.; Zhang, S.; Williams, B.R.; Major, J.; Hamilton, T.A.; Fenton, M.J.; et al. TLR4, but not TLR2, mediates IFN- $\beta$-induced STAT1 $\alpha / \beta$-dependent gene expression in macrophages. Nat. Immunol. 2002, 3, 392-398. [CrossRef] [PubMed]

30. Eskan, M.A.; Rose, B.G.; Benakanakere, M.R.; Lee, M.J.; Kinane, D.F. Sphingosine 1-phosphate 1 and TLR4 mediate IFN- $\beta$ expression in human gingival epithelial cells. J. Immunol. 2008, 180, 1818-1825. [CrossRef] [PubMed]

31. Kato, A.; Ogasawara, T.; Homma, T.; Saito, H.; Matsumoto, K. Lipopolysaccharide-binding protein critically regulates lipopolysaccharide-induced IFN-beta signaling pathway in human monocytes. J. Immunol. 2004, 172, 6185-6194. [CrossRef] [PubMed]

32. Zeng, L.; Liu, Y.P.; Sha, H.; Chen, H.; Qi, L.; Smith, J.A. XBP-1 couples endoplasmic reticulum stress to augmented IFN-beta induction via a cis-acting enhancer in macrophages. J. Immunol. 2010, 185, 2324-2330. [CrossRef] [PubMed]

33. Lamkanfi, M.; Dixit, V.M. Mechanisms and functions of inflammasomes. Cell 2014, 157, $1013-1022$. [CrossRef] [PubMed]

34. Guo, H.; Callaway, J.B.; Ting, J.P. Inflammasomes: Mechanism of action, role in disease, and therapeutics. Nat. Med. 2015. [CrossRef] [PubMed]

35. Zhang, L.; Zhu, T.; Qian, F.; Xu, J.; Dorje, G.; Zhao, Z.; Guo, F.; Li, Y. Iridoid glycosides isolated from Scrophularia dentata Royle ex Benth. and their anti-inflammatory activity. Fitoterapia 2014, 98, 84-90. [CrossRef] [PubMed]

Sample Availability: Not avaliable.

(C) 2015 by the authors; licensee MDPI, Basel, Switzerland. This article is an open access article distributed under the terms and conditions of the Creative Commons by Attribution (CC-BY) license (http://creativecommons.org/licenses/by/4.0/). 